\title{
On Human Autonomic Nervous Activity Related to Weather Conditions Based on Big Data Measurement via Smartphone
}

\author{
Makoto Komazawa ${ }^{1,2}$, Kenichi Itao ${ }^{2,3}$, Hiroyuki Kobayashi' ${ }^{3}$, Zhiwei Luo ${ }^{4}$ \\ ${ }^{1}$ Graduate School of System Informatics, Kobe University, Kobe, Japan \\ ${ }^{2}$ WINFrontier Co. Ltd., Tokyo, Japan \\ ${ }^{3}$ JUNTENDO University, Tokyo, Japan \\ ${ }^{4}$ Organization of Advanced Science and Technology Kobe University, Kobe, Japan \\ Email: makoto.komazawa@winfrontier.com
}

Received 6 May 2016; accepted 21 June 2016; published 24 June 2016

Copyright (C) 2016 by authors and Scientific Research Publishing Inc.

This work is licensed under the Creative Commons Attribution International License (CC BY). http://creativecommons.org/licenses/by/4.0/

(c) (7) Open Access

\section{Abstract}

This research uses our previously-developed smartphone camera-based heart rate change analysis system to survey the correlation between weather patterns and the autonomic nervous activity across a big data set of approximately 200,000 entries. The results showed a trend in which a significant decrease was seen in sympathetic nervous activity in both males and females-the higher the temperature. In addition, a significant increase was seen in the sympathetic nervous system in both males and females-the higher the atmospheric pressure. Lastly, a significant decrease was seen in the sympathetic nervous system in both males and females-the more precipitation there was. These results accord with prior research and with human biological phenomena, and we were able to use a data set of approximately 200,000 entries to statistically demonstrate our hypothesis. We believe this represents a valuable set of reference data for use in the health care.

\section{Keywords}

Heart Rate Variability, Autonomic Nervous System, Large Amount of Measurement Data, Weather

\section{Introduction}

It has long been recognized that modern society is stressful. If human beings are subjected to stress for a long period, the functions of autonomic nervous system and the endocrine system, which control the adrenocortical hormone, will be seriously influenced [1]. The autonomic nervous system controls the balance between the 
sympathetic nerve activity, which responses for maintaining the tension and excitement, and the parasympathetic nerve activity, which responses for maintaining relaxation. Therefore, it is very important for self-management to routinely recognize the state of our autonomic nervous system during everyday life [2].

The typical non-invasive technique for measuring autonomic nervous system uses a small, specialized heart rate sensor [3], or a fingertip pulse wave sensor [4]. These devices are used to measure RR interval (heartbeat interval) and peak interval (a value corresponding to the RR interval that is detected from the pulse waveform) [5], whereupon heart rate variability analysis is performed to calculate sympathetic nervous and parasympathetic nervous activity indicators [6]. These systems use Fast Fourier Transform (FFT) [7] to calculate the autonomic nervous activity from RR interval data in one to five minutes.

However, all these products use extremely expensive, specialized sensors and systems to measure RR intervals and pulse wave peak intervals. Thus, the hurdles to their use by the general public are high. Because of this, measurement of autonomic nervous system conditions has been limited to specialized facilities such as hospitals.

During previous research, authors developed a simple and precise measurement system that does not rely on specialized devices, but utilizes the camera of smartphones sold on the general market [8]. In this system, the device camera is placed on the tip of the finger for a short amount of time (just over 30 seconds), where it detects the pulse waveform peak interval from luminance changes in blood flow. Then, heart rate variability analysis is performed to measure the detailed conditions of the autonomic nervous system, namely, its balance and amount of activity (total power).

This system is currently being put to use by approximately 1,000,000 users (as of March 2016) [9] as an App for their iPhone (Apple Inc.) [10] or Android device (Google Inc.) [11].

Up to this point, autonomic nervous system measurements have been mainly conducted at hospitals, laboratories, and other facilities, using specialized sensors and equipment. Thus, the number of possible measurement subjects was limited to few hundred people at most. And as measurements were conducted under a particular set of circumstances, they cannot be considered an accurate representation of autonomic nervous system in daily life.

The system utilized in this study, however, is able to easily measure a large amount of data at any time, any location, and after any activity, giving researchers an understanding of autonomic nervous system conditions under everyday circumstances.

The authors used this system in previous research to investigate the relationship between autonomic nervous system and age and BMI, based on approximately 100,000 entries of autonomic nervous system data. This study found that the autonomic nervous activity decreases significantly as age and BMI increase [12]. The authors also published a study on the diurnal variation of autonomic nervous system, based on approximately 100,000 entries of autonomic nervous system data [13]. The results of these studies are consistent with results obtained using specialized sensors and measurement equipment.

While there is a comparatively high volume of research [14] [15] on the correlation between atmospheric temperature (one aspect of weather) and changes in the human body, there remains little research into other factors like atmospheric pressure and precipitation.

Studies on all of these factors have involved small samples sizes, so there was as yet no research that utilized a big data set of several hundreds of thousands of entries to analyze the relationship of weather to the autonomic nervous system.

This research uses an unprecedented set of approximately 200,000 entries of data on the autonomic nervous system and analyzes it according to the three parameters below.

- The relationship between autonomic nervous system and atmospheric temperature

- The relationship between autonomic nervous system and atmospheric pressure

- The relationship between autonomic nervous system and precipitation

\section{Methods}

This study employed a heart rate variability analysis system utilizing the camera of smartphones [8]. In this system, the smartphone camera is placed against the tip of the finger, where it continuously acquires data on the luminance of the skin. If the finger is lifted from the camera, the system displays a warning message. A pulse wave is derived from the changes in luminance, and the peak interval (corresponds to the RR interval) is detected from that pulse waveform. Then, frequency analysis is performed on peak interval fluctuations to calcu- 
late the autonomic nervous system indicator. This system is outlined in Figure 1.

The frequency analysis conformed to the procedure described in [6], with the low frequency component (LF) calculated as $0.04 \mathrm{~Hz}-0.15 \mathrm{~Hz}$, and the high frequency component (HF) calculated as $0.15 \mathrm{~Hz}-0.4 \mathrm{~Hz}$.

$\mathrm{LF} / \mathrm{HF}$ values are used as indicators of sympathetic nervous activity, as well as indicators of tension, stimulation, and stress [6].

This paper analyzes the autonomic nervous system data of 53,800 subjects (17,474 males and 36,326 females). Measurement data was used with the consent of the subjects, in accordance with the ethics regulations of WIN Frontier Co., Ltd.

Subject age (in tens of years) and sex are displayed in Table 1. IBM SPSS Statics Version 22 was used for this study's statistical processing. The significance level was set to $5 \%$.

\section{The Relation between Autonomic Nervous System and Atmospheric Temperature}

This research surveys the relationship of atmospheric pressure to autonomic nervous system. Data on atmospheric temperature averages was downloaded from the Japan Meteorological Agency's website [16] and the date of measurements and data from each prefecture tied to measured values by city as grouped by ordinance-designated city. The temperature intervals were grouped around days measuring 25 degrees Celsius, or what is called a "summer's day" [17], with categories for days below 25 degrees and above 25 degrees, respectively. Data by
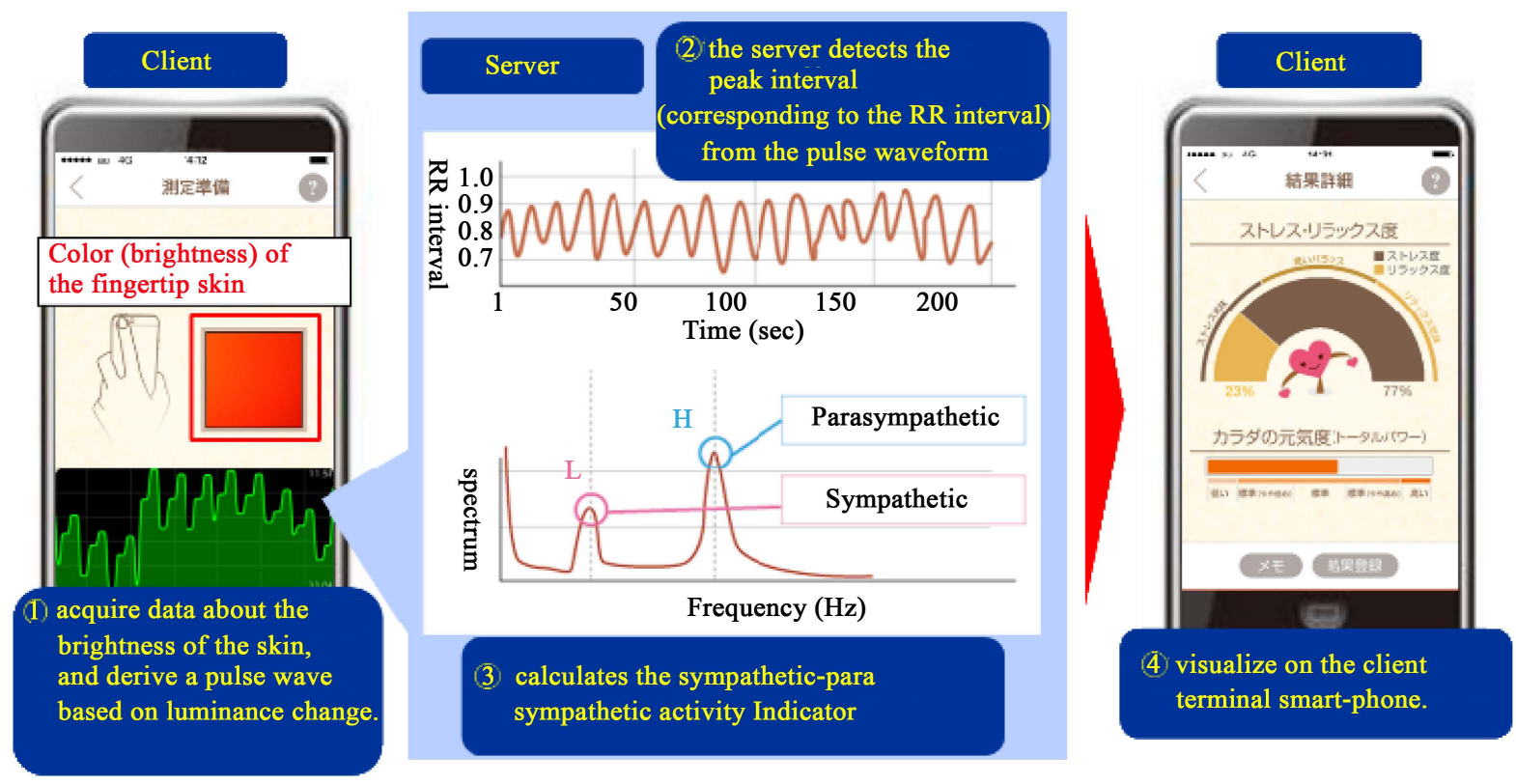

Figure 1. System outline.

Table 1. Subject age (in tens of years) and sex.

\begin{tabular}{cccc}
\hline Age & Man & Female & Total \\
\hline 10 's & 1890 & 6333 & 8223 \\
20 's & 2530 & 8746 & 11,276 \\
30 's & 2326 & 4862 & 7188 \\
40 's & 4584 & 8723 & 13,307 \\
50 's & 4633 & 6524 & 11,157 \\
Over 60's & 1511 & 1138 & 2649 \\
Total & 17,474 & 36,326 & 53,800 \\
\hline
\end{tabular}


temperature category is seen in Table 2.

It has been reported that treating LF/HF, an index of sympathetic nervous activity, as a logarithm normalizes data [18], so LF/HF for each data entry was converted to the LnLF/HF logarithm, and the difference in population mean between each was analyzed. Results for males are seen in Table 3 and Figure 2, and those for females in Table 4 and Figure 3.

The results show a trend in which there is a significant drop in sympathetic nervous activity in both males and females the higher the temperature is (P value: < statistical significance 0.05 ).

In general, it is understood that in cold weather, the effects of the sympathetic nervous system constrict the blood vessels and prevent the body from dispersing heat; in warm weather, the parasympathetic nervous system expands the blood vessels and causes the body to perspire, thereby decreasing body temperature [19]. This research hypothesized that a similar biological phenomenon would be present in the autonomic nervous system and manifest similar heat- and cold-prevention mechanisms. We were able to utilize a large set of 200,000 entries of data to statistically demonstrate this.

We believe this represents an extremely useful set of reference data that can be used for adjusting day-to-day lifestyles to account for temperature increases, to control health, et cetera.

\section{The Relation between Autonomic Nervous System and Atmospheric Pressure}

In this section, we examine the relationship between atmospheric pressure and the autonomic nervous system. Data on atmospheric pressure averages was downloaded from the Japan Meteorological Agency's website [16] and the date of measurements and data from each prefecture tied to measured values by city as grouped by ordinance-designated city. The pressure intervals were grouped around readings of $1013 \mathrm{hPa}$ for one unit of pressure,

Table 2. Data by temperature category.

\begin{tabular}{cccc}
\hline Temperature & Man & Female & Total \\
\hline Under $25^{\circ} \mathrm{C}$ & 74,100 & 150,767 & 224,867 \\
Over $25^{\circ} \mathrm{C}$ & 3818 & 12,500 & 16,318 \\
Total & 77,918 & 163,267 & 241,185 \\
\hline
\end{tabular}

Table 3. T-test results: atmospheric temperature and LnLF/HF (male).

\begin{tabular}{cccccc}
\hline \multicolumn{5}{c}{ Group Statistics } \\
\hline & Temperature_flag & $\mathrm{N}$ & Mean & Std Deviation & Sid Error Mean \\
\hline \multirow{2}{*}{ LnLF/HF } & Under $25^{\circ} \mathrm{C}$ & 74,100 & 0.5041853460 & 0.9161316994 & 0.003365494 \\
& Over $25^{\circ} \mathrm{C}$ & 3818 & 0.4466678728 & 0.8858146424 & 0.0143358977 \\
\hline
\end{tabular}

\begin{tabular}{ccc}
\hline & & Levene’s Test for Equality of Variances \\
\hline LnLF/HF & Equal variances assumed & Fig. \\
\cline { 2 - 3 } & Equal variances not assumed & 7.66 \\
\hline
\end{tabular}

Independent Samples Test

\begin{tabular}{|c|c|c|c|c|c|c|}
\hline \multicolumn{7}{|c|}{ t-test for Equality of Means } \\
\hline \multirow[b]{2}{*}{$\mathrm{t}$} & \multirow[b]{2}{*}{$\mathrm{df}$} & \multirow[b]{2}{*}{ 3lg. (2-talled) } & \multirow{2}{*}{$\begin{array}{c}\text { Mean } \\
\text { Difference }\end{array}$} & \multirow{2}{*}{$\begin{array}{c}\text { St }<\text { J. Error } \\
\text { Difference }\end{array}$} & \multicolumn{2}{|c|}{$\begin{array}{l}\text { 95\% Confidence Interval of the } \\
\text { Difference }\end{array}$} \\
\hline & & & & & Lower & Upper \\
\hline 3.789 & 77,916 & 0.000 & 0.0575174732 & 0.0151794567 & 0.0277658320 & 0.0872691143 \\
\hline 3.906 & 4248.655 & 0.000 & 0.0575174732 & 0.0147256413 & 0.0286475221 & 0.0863874242 \\
\hline
\end{tabular}


Table 4. T-test results: atmospheric temperature and LnLF/HF (female).

\begin{tabular}{|c|c|c|c|c|}
\hline Temperature_flag & $\mathrm{N}$ & Mean & Std. Deviation & Std. Error Mean \\
\hline $\mathrm{LnLF} / \mathrm{HF}$ Under $25^{\circ} \mathrm{C}$ & 150,767 & 0.3745794716 & 0.9287018287 & 0.0023917906 \\
\hline Over $25^{\circ} \mathrm{C}$ & 12,500 & 0.3520963961 & 0.8932121169 & 0.0079891320 \\
\hline & & \multicolumn{3}{|c|}{ Levene’s Test for Equality of Variances } \\
\hline & & \multicolumn{2}{|c|}{$\mathrm{F}$} & Sig. \\
\hline $\mathrm{LnLF} / \mathrm{HF}$ & $\begin{array}{l}\text { assumed } \\
\text { lot assumed }\end{array}$ & \multicolumn{2}{|c|}{25.065} & 0.000 \\
\hline
\end{tabular}

Independent Samples Test

\begin{tabular}{cccccccc}
\hline & \multicolumn{3}{c}{ Test for Equality of Means } \\
\hline $\mathrm{t}$ & $\mathrm{df}$ & Sig. (2-tailed) & $\begin{array}{c}\text { Mean } \\
\text { Difference }\end{array}$ & $\begin{array}{c}\text { Std. Error } \\
\text { Difference }\end{array}$ & \multicolumn{2}{c}{$\begin{array}{c}\text { 95\% Confidence Interval of the } \\
\text { Difference }\end{array}$} \\
\hline 2.608 & 163,265 & 0.009 & 0.0224830755 & 0.0086192105 & 0.0055896134 & 0.0393765376 \\
\hline 2.696 & $14,830.070$ & 0.007 & 0.0224830755 & 0.0083394780 & 0.0061366649 & 0.0388294861 \\
\hline
\end{tabular}

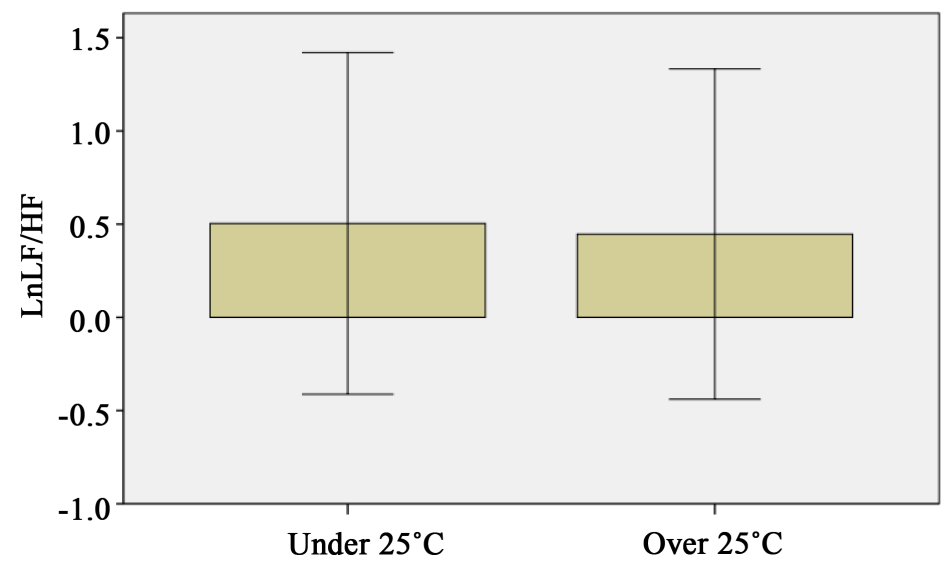

Figure 2. Relation between atmospheric temperature and LnLF/HF (male).

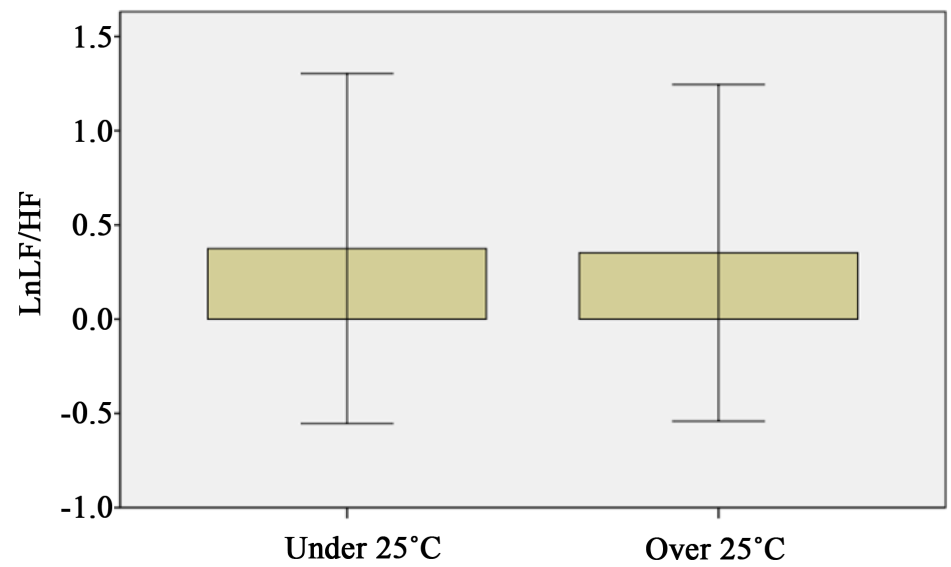

Figure 3. Relation between atmospheric temperature and LnLF/HF (female). 
with categories for days below $1013 \mathrm{Hpa}$ and above $1013 \mathrm{Hpa}$, respectively. Data by pressure category is shown in Table 5.

LF/HF for each entry was converted to the LnLF/HF logarithm, and the difference in population mean between each was analyzed. Results for males are seen in Table 6 and Figure 4, and those for females in Table 7 and Figure 5.

The results show a trend in which there is a significant increase in sympathetic nervous activity in both males and females the higher the pressure is ( $\mathrm{P}$ value $<$ statistical significance 0.0 .5 )

According to prior research, low pressure systems associated with weather irregularity increase parasympathetic nervous activity, such as in bradycardia, decreased granulocytes, increased lymphocytes, decreased urinary adrenaline, et cetera. The body becomes sluggish and one feels depressed [20] [21] in high pressure systems associated with fair weather, there is increased sympathetic nervous activity, with exacerbated release of dopamine in the corpus striatum, exacerbated release of peripheral catecholamine, et cetera, causing one to feel comfortable and at ease [20] [22]. In this way, this research shows similar trends to those found in prior research, and we were able to successfully use the data set of approximately 200,000 entries to statistically demonstrate this autonomic nervous system function. We believe this represents an extremely useful set of reference data that can be used for adjusting day-to-day lifestyles to account for atmospheric pressure changes, to control health, et cetera.

\section{The Relation between Autonomic Nervous System and Precipitation}

In this section, we examine the relationship between precipitation and the autonomic nervous system. Data on atmospheric pressure averages was downloaded from the Japan Meteorological Agency's website [16] and the

Table 5. Data by atmospheric pressure category.

\begin{tabular}{cccc}
\hline Pressure & Man & Female & Total \\
\hline Under 1013 Hpa & 40,984 & 87,558 & 128,542 \\
Over 1013 Mpa & 36,934 & 75,709 & 112,643 \\
Total & 77,918 & 163,267 & 241,185 \\
\hline
\end{tabular}

Table 6. T-test data: atmospheric pressure and LnLF/HF (male).

Group Statistics

\begin{tabular}{cccccc}
\hline & HPAJag & $\mathrm{N}$ & Mean & Std. Deviation & Std. Error Mean \\
\hline \multirow{2}{*}{ LnLF/HF } & Under 1013 Hpa & 40,964 & 0.4836457632 & 0.9072410738 & 0.0044814188 \\
& Over 1013 Hpa & 36,934 & 0.5210314105 & 0.9226212556 & 0.0048007632 \\
\hline
\end{tabular}

\begin{tabular}{ccc}
\hline & & Levene’s Test for Equality of Variances \\
LnLF/HF & Equal variances assumed & F \\
\hline
\end{tabular}

Independent Samples Test

\begin{tabular}{|c|c|c|c|c|c|c|}
\hline \multicolumn{7}{|c|}{ Test for Equality of Means } \\
\hline \multirow{2}{*}{$\mathrm{t}$} & \multirow{2}{*}{ df } & \multirow{2}{*}{$\begin{array}{l}\text { Sig. } \\
\text { (2-tailed) }\end{array}$} & \multirow{2}{*}{ Mean Difference } & \multirow{2}{*}{ Std. Error Difference } & \multicolumn{2}{|c|}{$\begin{array}{l}\text { 95\% Confidence Interval of the } \\
\text { Difference }\end{array}$} \\
\hline & & & & & Lower & Upper \\
\hline-5.698 & 77,916 & 0.000 & -0.037385647 & 0.0065616416 & -0.050246424 & -0.024524870 \\
\hline-5.693 & $76,794.088$ & 0.000 & -0.037385647 & 0.0065673771 & -0.050257669 & -0.024513626 \\
\hline
\end{tabular}


Table 7. T-test data: atmospheric pressure and LnLF/HF (female).

Group Statistics

\begin{tabular}{|c|c|c|c|c|c|}
\hline \multicolumn{2}{|c|}{ HPA_flag } & $\mathrm{N}$ & Mean & Std. Deviation & Std. Error Mean \\
\hline \multirow{4}{*}{$\mathrm{LnLF} / \mathrm{HF}$} & Under 1013 Нра & 87,558 & 0.362064544 & 0.917884073 & 0.003101987 \\
\hline & Over 1013 Нра & 75,709 & 0.385340987 & 0.935254525 & 0.003399038 \\
\hline & & & & \multicolumn{2}{|c|}{ Levene's Test for Equality of Variances } \\
\hline & & & & $\mathrm{F}$ & Sig. \\
\hline \multicolumn{2}{|c|}{ LnLF/HF } & $\begin{array}{l}\text { al varianc } \\
\text { variances }\end{array}$ & $\begin{array}{l}\text { ed } \\
\text { med }\end{array}$ & 22.594 & 0.000 \\
\hline
\end{tabular}

Independent Samples Test

\begin{tabular}{|c|c|c|c|c|c|c|}
\hline \multirow{3}{*}{$\mathrm{t}$} & \multicolumn{6}{|c|}{ t-test for Equality of Means } \\
\hline & \multirow{2}{*}{ df } & \multirow{2}{*}{ Sig (2-tailed) } & \multirow{2}{*}{ Mean Difference } & \multirow{2}{*}{ Std. Error Difference } & \multicolumn{2}{|c|}{$\begin{array}{l}\text { 95\% Confidence Interval of the } \\
\text { Difference }\end{array}$} \\
\hline & & & & & Lower & Upper \\
\hline-5.065 & 163,265 & 0.000 & -0.023276443 & 0.0045954590 & -0.032283441 & -0.014269445 \\
\hline-5.058 & $158,978.471$ & 0.000 & -0.023276443 & 0.0046017152 & -0.032295705 & -0.014257181 \\
\hline
\end{tabular}

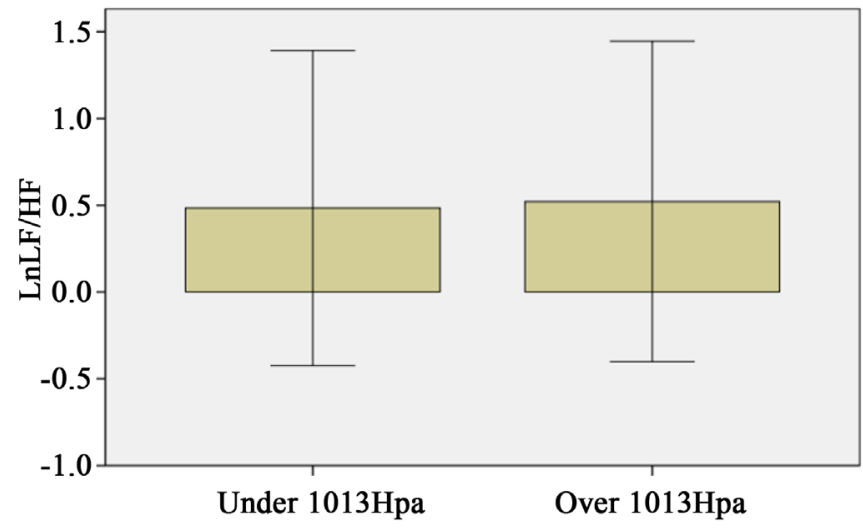

Figure 4. Relation between atmospheric pressure and LnLF/HF (male).

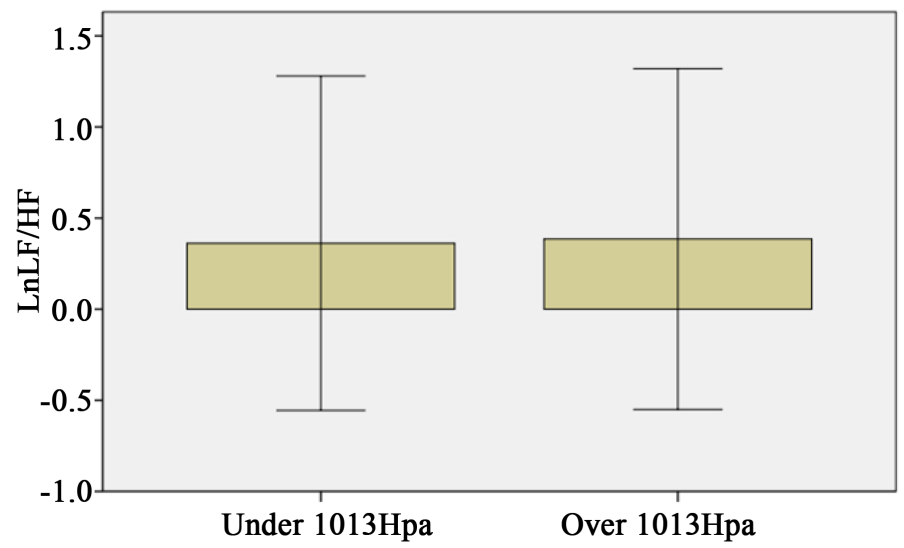

Figure 5. Relation between atmospheric pressure and LnLF/HF (female). 
date of measurements and data from each prefecture tied to measured values by city as grouped by ordinancedesignated city.

The precipitation intervals were grouped around $10 \mathrm{~mm}$ of precipitation in a 24-hour period, with categories for days below $10 \mathrm{~mm}$ and above $10 \mathrm{~mm}$, respectively. Data by precipitation is shown in Table 8 .

$\mathrm{LF} / \mathrm{HF}$ for each entry was converted to the LnLF/HF algorithm, and the difference in population mean between each was analyzed. Results for males are seen in Table 9 and Figure 6, and those for females in Table 10 and Figure 7.

The results show a trend in which there is a significant increase in sympathetic nervous activity in both males and females the more rain there is (P value $<$ statistical significance 0.05 ).

In general, it is understood that on days with fair weather, there is more oxygen in the atmosphere, and this increases oxygen pressure in the bloodstream, causing the body to prioritize sympathetic nervous activity; by contrast, on cloudy days with poor weather, there is less oxygen, and this decreases oxygen pressure in the bloodstream, causing the body to prioritize parasympathetic nervous activity [20]-[22]. This research hypothesized that a similar biological phenomenon would be present in the autonomic nervous system. We believe this represents an extremely useful set of reference data that can be used for adjusting day-to-day lifestyles to account for precipitation changes, to control health, et cetera.

\section{Conclusions}

In this research, we used our previously-developed smartphone camera-based heart rate change analysis system [8] to survey the correlation between weather patterns and the autonomic nervous system across a big data set of approximately 200,000 entries.

Table 8. Data by precipitation volume.

\begin{tabular}{cccc}
\hline Precipitation & Man & Female & Total \\
\hline Under $10 \mathrm{~mm}$ & 74,536 & 153,634 & 228,170 \\
Over $10 \mathrm{~mm}$ & 3382 & 9633 & 13,015 \\
Total & 77,918 & 163,267 & 241,185 \\
\hline
\end{tabular}

Table 9. T-test data: precipitation and LnLF/HF (male).

Group Statistics

\begin{tabular}{|c|c|c|c|c|c|}
\hline Pre & lag & $\mathrm{N}$ & Mean & Std. Deviation & Sid. Error Mean \\
\hline \multirow{4}{*}{ LnLF/HF } & Under 10 mm & 74,536 & 0.503473688 & 0.9158507122 & 0.0033546070 \\
\hline & Over $10 \mathrm{~mm}$ & 3382 & 0.4549370943 & 0.8889709991 & 0.0152862441 \\
\hline & & & \multicolumn{3}{|c|}{ Levene’s Test for Equality of Variances } \\
\hline & & & $\mathrm{F}$ & & \\
\hline \multirow[b]{2}{*}{$\mathrm{LnLF} / \mathrm{HF}$} & Equal var & umed & \multirow[b]{2}{*}{2.923} & \multirow{2}{*}{\multicolumn{2}{|c|}{0.087}} \\
\hline & \multicolumn{2}{|c|}{ Equal variances not assumed } & & & \\
\hline
\end{tabular}

Independent Samples Test

\begin{tabular}{|c|c|c|c|c|c|c|}
\hline \multicolumn{7}{|c|}{ t-test for Equality of Means } \\
\hline \multirow{2}{*}{$\mathrm{t}$} & \multirow[t]{2}{*}{ df } & \multirow{2}{*}{ Sig. (2-tailed) } & \multirow{2}{*}{ Mean Difference } & \multirow{2}{*}{$\begin{array}{l}\text { Std. Error } \\
\text { Difference }\end{array}$} & \multicolumn{2}{|c|}{$\begin{array}{l}\text { 95\% Confidence Interval of the } \\
\text { Difference }\end{array}$} \\
\hline & & & & & Lower & Upper \\
\hline 3.018 & 77,916 & 0.003 & 0.0485365939 & 0.0160815563 & 0.0170168431 & 0.0800563447 \\
\hline 3.101 & 3714.105 & 0.002 & 0.0485365939 & 0.0156500047 & 0.0178531491 & 0.0792200387 \\
\hline
\end{tabular}


Table 10. T-test data: precipitation and LnLF/HF (female).

Group Statistics

\begin{tabular}{cccccc}
\hline \multicolumn{2}{c}{ Precipitation_Flag } & N & Mean & Std. Deviation & Std. Error Mean \\
\hline \multirow{2}{*}{ LnLF/HF } & Under 10 mm & 153,634 & 0.3762990589 & 0.9268479336 & 0.0023646388 \\
& Over 10 mm & 9633 & 0.3179797096 & 0.9115128369 & 0.0092871404 \\
\hline & & & Levene's Test for Equality of Variances \\
LnLF/HF & Equal variances assumed & F & Sig. \\
\hline
\end{tabular}

Independent Samples Test

\begin{tabular}{|c|c|c|c|c|c|c|}
\hline \multicolumn{7}{|c|}{ t-test for Equality of Means } \\
\hline \multirow{2}{*}{$\mathrm{t}$} & \multirow{2}{*}{ (Jf) } & \multirow{2}{*}{ Sig (2-tailed) } & \multirow{2}{*}{ Mean Difference } & \multirow{2}{*}{ Std. Error Difference } & \multicolumn{2}{|c|}{$\begin{array}{l}\text { 95\% Confidence Interval of the } \\
\text { Difference }\end{array}$} \\
\hline & & & & & Lower & Upper \\
\hline 5.997 & 163,265 & 0.000 & 0.0583193492 & 0.0097255108 & 0.0392575630 & 0.0773811354 \\
\hline 6.085 & $10,918.459$ & 0.000 & 0.0583193492 & 0.0095834489 & 0.0395340521 & 0.0771046464 \\
\hline
\end{tabular}

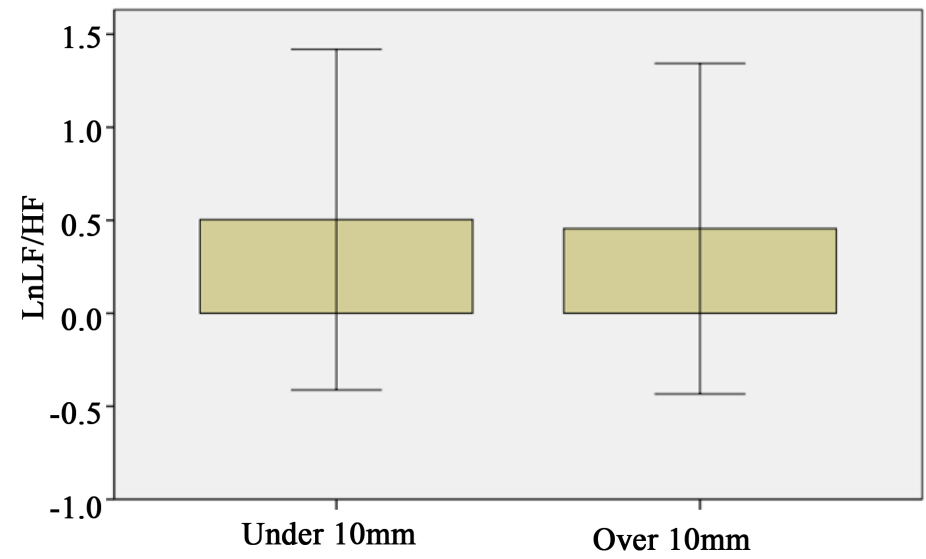

Figure 6. Relation between precipitation and LnLF/HF (male).

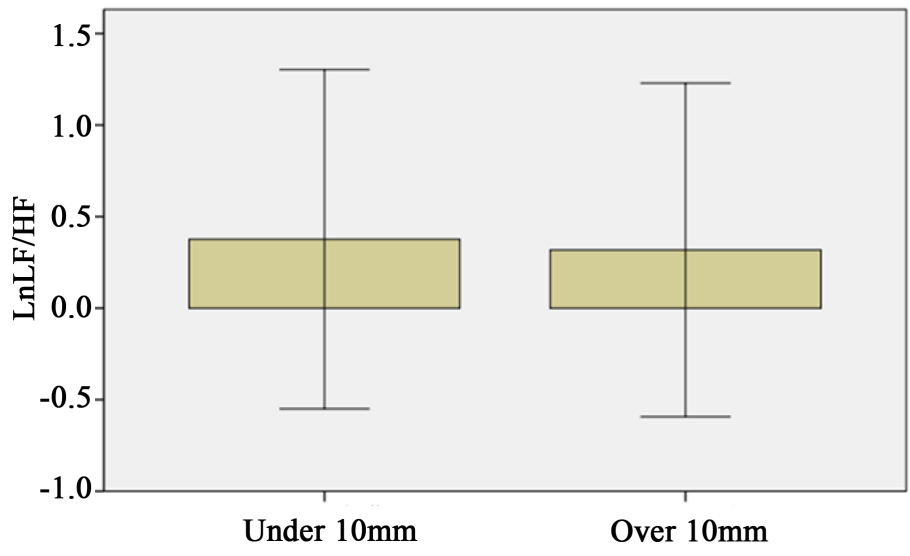

Figure 7. Relation between precipitation and LnLF/HF (female). 
The results showed a trend in which a significant decrease was seen in sympathetic nervous activity in both males and females- the higher the temperature. In addition, a significant increase was seen in the sympathetic nervous system in both males and females-the higher the atmospheric pressure. Lastly, a significant decrease was seen in the sympathetic nervous system in both males and females- the more precipitation there was. These results accord with prior research and with human biological phenomena, and we were able to use a data set of approximately 200,000 entries to statistically demonstrate our hypothesis. We believe this represents a valuable set of reference data for use in the health care.

Our smartphone camera-based heart rate change analysis system [8] is accreting several tens of thousands of new data points on the autonomic nervous system daily. Once the data exceeds one million entries, we believe we will be in a position to conduct a more fine-grained analysis of the impact of autonomic nervous system function in daily life.

\section{References}

[1] Onaka, T. (2005) Stress and Its Neural Mechanisms. Journal of Pharmacological Sciences, 126, 170-173.

[2] Itao, K. and Komazawa, M. (2015) Wearable Device Applications and Technology Tends. Japan Institute of Electronics Packaging, Special Issue, 18, 384-389.

[3] Union Tool Co. (2013) Wearable Heart Rate Sensor WHS-1. http://uniontool.co.jp/product/sensor/index_02.html

[4] WIN Frontier Co. Ltd. (2013) Lifescore Quick. http://www.winfrontier.com/lifescorequick.html

[5] Fumio, M., et al. (2001) Basic Research to Estimate Athlete’s Psychological Stress Responses by Digital Plethysmography. Research Bulletin, 29, 87/102.

[6] Task Force of the European Society of Cardiology and the North American Society of Pacing and Electrophysiology. (1996) Heart Rate Variability: Standards of Measurement, Physiological Interpretation, and Clinical Use. Circulation, 93, 1043-1065. http://dx.doi.org/10.1161/01.CIR.93.5.1043

[7] Mikio, H. (2010) Spectral Analysis. AsakuraPub, Tokyo.

[8] Komazawa, M., Itao, K. and Luo, Z. (2015) Development of Heart Rate Variability Analysis System Using a SmartPhone Camera. 20th Poster Presentation Collection of the Academy of Human Informatics, 19-20.

[9] Kobayashi, H. (2016) COCOLOLO: Autonomic Nervous System Are Complete by the Stress Check of the Heart in 30 Seconds. GOMA BOOK Co., Ltd. http://www.goma-books.com/archives/36436

[10] WIN Frontier Co., Ltd. (2015r) COCOLOLO—Check 8 Types of Feelings with the Fluctuation of the Heart Rate. https://itunes.apple.com/jp/app/cocololo-cafe-kimochishea/id973325431?mt=8\&ign-mpt=uo\%3D4

[11] WIN Frontier Co., Ltd. (2015) COCOLOLO $\bullet$ Heart Furnace-Stress Check Using the Fluctuation of Heart Rate. https://play.google.com/store/apps/details?id=com. winfrontier.COCOLOLO\&hl=ja

[12] Komazawa, M., Itao, K. and Luo, Z. (2015) The Relationship between Autonomic Nervous System and Age, BMI Based on about 100,000 of Measurement Data. $21^{\text {st }}$ Poster Presentation Collection of the Academy of Human Informatics, 24-25.

[13] Komazawa, M., Itao, K. and Luo, Z. (2015) The Relationship between Autonomic Nervous System and Circadian rhythm Based on about 100,000 of Measurement Data. 22nd Poster Presentation Collection of the Academy of Human Informatics, 14-15.

[14] Okada, M. and Kakehashi, M. (2014) Effects of Outdoor Temperature on Changes in Physiological Variables before and after Lunch in Healthy Women. International Journal of Biometeorology, 58, 1973-1981.

[15] Ren, C., O’Neill, M.S., Park, S.K., Sparrow, D., Vokonas, P. and Schwartz, J. (2011) Ambient Temperature, Air Pollution, and Heart Rate Variability in an Aging Population. American Journal of Epidemiology, 173, 1013-1021.

[16] Japan Meteorological Agency. http://www.data.jma.go.jp/gmd/risk/obsdl/

[17] Japan Meteorological Agency. http://www.jma.go.jp/jma/kishou/know/yougo_hp/kion.html

[18] Yukishita, T., Lee, K., Kim, S., Yumoto, Y., Kobayashi, A., Shirasawa, T. and Kobayashi, H. (2010) Age and Sex-Dependent Alterations in Heart Rate Variability: Profiling the Characteristics of Men and Women in Their 30s. Anti-Aging Medicine, 7, 94-99. http://dx.doi.org/10.3793/jaam.7.94

[19] Kobayashi, H. (2011) Why “This” Is of Good Health? Sunmark Publishing Inc.

[20] Fukuda, M., Moroda, T., Toyabe, S., Iiai, T., Kawachi, Y., Takahashi, H., Iwanaga, T., Okada, M. and Abo, T. (1996) Granulocytosis Induced by Increasing Sympathetic Nerve Activity Contributes to the Incidence of Acute Appendicitis. Biomedical Research, 17, 171-181. http://dx.doi.org/10.2220/biomedres.17.171 
[21] Yukiokaetc, M. (2010) Effect of Changes of Atmospheric Pressure on the Autonomic Nervous of Rheumatoid Arthritis. Clinical Rheumatology, 22, 32-36.

[22] Fechtali, T, Abraini, J.H., Kriem, B. and Rostain, J.C. (1994) Pressure Increases de Novo Synthesized Striatal Dopamine Release in Free-Moving Rats. Neuroreport, 5, 725-728. http://dx.doi.org/10.1097/00001756-199402000-00017

\section{Submit or recommend next manuscript to SCIRP and we will provide best service for you:}

Accepting pre-submission inquiries through Email, Facebook, Linkedin, Twitter, etc A wide selection of journals (inclusive of 9 subjects, more than 200 journals)

Providing a 24-hour high-quality service

User-friendly online submission system

Fair and swift peer-review system

Efficient typesetting and proofreading procedure

Display of the result of downloads and visits, as well as the number of cited articles

Maximum dissemination of your research work

Submit your manuscript at: http://papersubmission.scirp.org/ 